Papers and Proceedings of the Royal Society of. Tasmania, Volume 115, 1981

(ms, received 8.2.1980)

\title{
JAMES MEEHAN'S SURVEY OF HOBART TOWN IN 1811
}

by Frank Bolt

Kingston Beach, Tasmania

(with two text figures)

ABS'LRAC'T

BOLT, Frank., 1981 (30 ix): James Meehan's survey of Hobart Town in 1811. Fap. Froc. R. Soc. Tasm., 115, 5-18 (with two figs.). ISSN 0-80-4703. Kingston Beach,

Tasmania, Australia. https://doi.org/10.26749/rstpp.115.5

During his visit to Hobart rown in 1811, Governor Macquarie instructed Acting Surveyor James Meehan to make a design for the layout of this small but growing settlement on the shores of the Derwent River.

The field notes of Meehan's survey work executed as a result of these instructions were recently rediscovered and were analysed and plotted by the author, enabling him to show in map form his interpretation of these survey notes.

The resulting map portrays an interesting picture of Hobart Town during the Collins period which is not complete. This interpretation of Meehan's survey notes may encourage further studies.

\section{JAMES MEEHAN'S SURVEY OF HOBART TOWN}

After taking office in 1810 Governor Macquarie decided to make a personal inspection of Van Dieman's Land in general, and of Hobart Town in particular. He found on his arrival in Hobart (November 23rd, 1811) a collection of miserable huts interspersed with some structures built of brick, public buildings of an unsatisfactory quality, and a few muddy tracks and laneways, wandering at random across the hilly slopes, along several rivulets and the shores of Sullivans Cove. Obviously no building controls had been applied, no thought had been given to a desirable layout of the settlcment with suitably located roads, and no areas of land had been set aside for any specified public purpose.

This situation alarmed Macquarie, as his experience as an administrator led him to see clearly the dangers of a repetition of the rather confused manner in which Sydney had grown up along the cart tracks leading out into the bush. Macquarie almost certainly discussed the matter first with the local officers and merchants, and then issued instructions to surveyor James Meehan (who had come with Macquarie as a member of his party) "...to frame and mark out a regular Plan..." for the settlement(1-see References).

The possible implications of these instructions put Meehan in a difficult position. The superimposition of a new grid system of streets over the existing random development of Hobart Town would inevitably mean that some people would retain all or much of their land and improvements while others would have to start all over again. It also meant that the grid system of streets had to be extended from a predetermined baseline which could be located almost at will in such a manner that the property owners along this line would profit very much indeed with little fear of the probable losses that less fortunate (or less influential) occupiers of land were likely to suffer. Meehan also had to take into account the topography of the settlement and its surroundings - deep gullies and steep slopes were everywhere. It must have taken quite some mental effort to stand in semi-cleared bushland, trying to visualise a smooth carriageway lined on both sides with prosperous houses and cottages.

The speed with which Meehan executed his instructions is impressive. Macquarie and his party arrived on Saturday, November $23 \mathrm{rd}$ and on the following Tuesday Meehan was already at work defining the all-important base line from which he was to extend his "... regular Plan..." There are no entries for the next two days, but no doubt many hurried consultations took place on the locations where the future cross roads (Argyle, 
Elizabeth, Murray, Harrington Streets etc.) were to strike this base line street (now Macquarie Street). People such as Ingie, Murray, Birch and McAuley did very well from these discussions - there are references in Meehan's survey notes to stakes representing street coners, the locations of which were later slightly moved giving different dimensions to allotments which could now be sub-divided and sold. On the other hand, Meehan was also able to avoid the area where many tradesmen and small business people lived by locating the bush track leading to New Town (now Elizabeth Street) somewhat further to the northeast, thus necessitating the construction of a new bridge (Wellington Bridge, commenced in 1816).

It should also be noted that there are differences between the plan as approved by Macquarie and the city blocks as they are today. Although these differences are sma11 (some blocks are slightly larger or snaller than originally indicated on the 1811 plan), they are in nearly all instances significant in that they tend to favour an application of common sense rather than the inflexible execution of an instruction.

On Friday 25 th Meehan made a traverse survey encircling the small settlement (at the time counting about 1000 people in total), while on the following Saturday he again charted further details of development along his "New Street" baseline. On that same Saturday the major points of his work over the past few days were plotted on a sheet of cartridge paper, a tedious job, which according to the practice of that time, was very likely done by himself. The proposed streets then were superimposed on this plot, and the final drawing was finished with a coloured wash indicating building lines etc.

All this precise and painstaking work was even completed (in all probability in duplicate!) in time for Macquarie to scrawl his approval on the plan - at least, if we are to accept the date mentioned on the plan in his own handwriting!

The next day was a Sunday, but this did not prevent Macquarie from issuing the first town planning ordnance in Tasmania:

"His Excellency the Governor, having observed with much regret, since his arrival here, that the several Public and Private Buildings in Hobart Town have hitherto been erected in a very irregular manner and without any plan whatever, has judged it expedient, and essentially necessary for the better appearance of the Town itself, and the accommodation of the Inhabitants, to frame and mark out a regular plan for the future guidance and observance of all such Persons as may be permitted to reside and build in it. The Acting Surveyor has accordingly, by His Excellency's

Direction, marked out with Stakes, in appropriate Places, the different divisions of the Town, which is for the present to consist of a large Square nearly in the Center of it, and Seven Streets, three of them running nearly parallel the whole length of the Town, and the remaining four crossing the three long streets at right angles. 'The Governor has named the square George's Square, in honour of our most Gracious Sovereign, and has given the following names to the seven Streets, vizt. Liverpool, Collins and Macquarie are the names given to the three Iong Streets, Argyle, Elizabeth, Murray and Harrington being the names given to the four Cross Streets. Posts having Finger Boards, nailed on them, with the names of the Square and the several Streets, having been erected at their respective commencement and terminations to point the more accurately the direction of the Square and Streets, they are in future to be known and called by the names given to them. On the square it is intended at some future period to erect a Church and Court House or Town Hall and a Main Guard. It is also intended that a Public Market, under proper regulations, shall be held in the center of it every Saturday, as soon as it can be ascertained whether the set-

tlers are disposed to bring the Produce of their farms for sale to this weekly Public Market, the Square likewise as it consists of an extensive area, will answer for a Public Garrison Parade."(2).

This he followed up with a building ordnance, spelling out at the same time the conditions under which the settlers henceforward were permitted to receive and occupy land:

"No person in future is to presume to build a House of any description in Hobart Town without previously submitting a Plan thereof to the Commandant, and receiving 
Frank Bolt

his Sanction for erecting the same. Such persons as are able and willing to build Brick or Stone or weather boarded Houses, of two stories high, forty feet long by 16 feet broad in the clear, tiled or Shingled and properly Glazed, will be entitled, on entering into security for erecting such a Building within two years, to receive a Town Allotment of 100 Feet in Front and 132 feet in depth, with 21 years Lease of the same from the Governor in Chief. Such persons as are not able to build two Story Houses but are willing and able to erect houses of one story high, thirty six feet long by 14 feet broad in the clear, tiled or shingled and properly Glazed, on entering into security to erect the same within two years, shall be cntitled to receive a Fourcen year Lease from the Governor in Chief of a Town Allotment consisting of sixty feet in front and 132 feet in depth."(3).

Macquarie then mentions Meehan's plan the ink of which was hardly dry:

"His Excellency the Governor has delivered a Plan of the T'own, as now subdivided and laid out, to the Commandant for his own guidance and also for that of such Persons as may wish to receive Town Allotments and build Houses in Hobart Town and to this Plan such Persons are accordingly referred, j.t being His Excellency's positjve Orders that the new Plan in question shall be rigidly adhered and conformed to in every respect."(4).

After briefly indicating his wish that a signal station was to be erected on Mount Nelson, Macquarie then obviously decided that he had raised enough dust for some time to come and closed his proclamation by saying that he was now

".....under the necessity of setting out for Port Dalrymple tomorrow, and is sorry he cannot at present prolong his stay at this settlement; but he trusts he shall be able to visit it soon again, when he anticipates the pleasing hope of finding it greatly improved in every respect." (5).

In 1813 Meehan returned to Tasmania to solve many of the disputes and arguments which resulted from title descriptions made by earlier surveyors, which were not always clear. Meehan did a lot of work in Tasmania that year, and also enlarged and improved on his 1811 definition of the new streets in Hobart Town.

From his notes the gradual development of Davey, Barrack, Bathurst and Campbell Streets emerge. He also surveyed many new allotments of land made available to settlers as a result of Macquarie's proclamation of 1 December 1811 (see above). Other notes also contain some interesting sidelights on some of the problems he encountered during his surveying activities. Samples include:

(p. 87 - transcribed):

"... to Hanna Garrett: 139 along Murray Street to the corner of a new street, then 151 feet along that new street - this land to be in lieu of a house that is to be taken down".

(Note: this obviously was a straightforward case of compensation for a house located within the reservation for one of the new streets).

(p. 88 - transcribed):

"... from chainage 3.20 to $4.71 \frac{1}{2}$ an allotment to John Cenliff(?) who promises to build a two-storey brick house, and who will give securities to that effect".

(Note: a case of someone having applied for a block of land $100 \times 132$ feet to build on - see Macquarie's promises mentioned earlier).

of course there were other cases:

(p. 73) "... making half an acre for Mich. Lee, on behalf of himself and others a

Free Masons - having had that claim from Norfolk Island".

An entry on page 77 gives an interesting sidelight on the continuous arguments which Knopwood had with later administrators with regard to his land on Battery Point: "... to discover the quantity of land $\mathrm{Mr}$. Knopwood supposes himself possessed of, which should be 30 acres."

By this time the new street layout of the Hobart of today was beginning to show itself. Much of the old Hobart Town from the Collins period was rapidly disappearing and indeed, during the periods of Lt. Governors Davey and Sore11 (1812-1824) there are many 
references in the official documents and newspapers to convict gangs constructing roads and bridges, and to some of the problems relating to people having to move to new allotments (often containing uncleared bushland) because of their earlier houses were in the way of a new street.

Very little of the Hobart Town of the Collins period survives. In fact the only known stucture of that period still in existence is the Commissariat Store in Macquarie Street, recently adapted for use by the Tasmanian Museun and Art Gallery. Other remnants of this period may also still be in existence, but their recovery would alnost certainly involvo archaeological research.

There are a number of cadastral boundaries in central. Hobart which either definitely or almost certainly date back to the Collins period. They include the Sw boundary line of the Risby Brothers property in Collins Street (the old Government Garden), the rear boundary 1 ines of the OBM bookshop and adjacent properties in Collins Street (an early street), the Elizabeth Street end of the Cat and Fiddle Lane (a track along the 'Town Creek'), a rectangular parcel of land behind the Commonwealth Bank in Elizabeth Street (a small paddock facing an early lane), and certain cadastral lines in the area behind the Theatre Royal which, in all probability relate to early grants or leases to Matthew Bowden and others in that area. Several property boundary lines between the AMP building and the City Hall in all probability originate from the bush track that was formed when Collins and his soldiers, convicts and settlers forced their way from the landing place behind the present Hope and Anchor Hotel in Macquarie Street through the dense scrub to an area between the present GPO building and Hadley's Hotel. Soon this track became a pathway, then a lane and by 1811 it started to take on the appearance of a street lined with little cottages surrounded by paling fences.

The nap of early Hobart Town which accompanies this paper was based mainly on the information contained in the fieldnotes of the survey which Meehan did in 1811. Some supplementary detail however was taken from his 1813 survey, and use was also made of other documentary information dating from that period. However, great care was taken not to confuse the general situation portrayed by the map with information which is definitely of a later date. On the other hand, use was made of later material portraying a situation which, in all probability, also existed in 1811 . This material included a survey of about 1826 of the southern shoreline of Sullivans Cove(6), Lee Archer's map of 1827(7), and Capt. Welch's 1827 survey of Sullivans Cove(8), from which the fathom lines were compilied.

The reconstruction of the map of the swampy environment at the mouth of the Hobart Rivulet posed great difficulties, but a careful study of Lands Department Charts Hobart 4, 5, 12 and 37 provided much information, and the configuration now shown on the map should be close to the truth.

The reconstruction of Hunter Island was an interesting exercise. Early surveyors (including Meehan) didn't survey it precisely, but in the $1820^{\prime} \mathrm{s}$ a decision was made to take the gallows down, and subdivide the vacant space into allotments for warehouses. This subdivision found its way onto Lands Department Chart Hobart 12, and later again onto Hobart 37, and together with other supplementary information made it possible to reclefine the outline of the island, because this subdivision can still be found back on the ground. of the warehouses of that period however some, like Hunter Street Number 33, still exist: they date from about $1827(9)$.

Meehan's survey work in the area of the old Hobart Railway Station and Gasworks contains a number of bearings which cannot be reconciled with modern information and as a result the detail shown on the map around the lower end of Campbell Street may have to be slightly revised - if more exact information is ever discovered. Fortunately, Meehan picked up some cadastral detail near the area of the railway roundabout which survived for many decades and found its way onto other title surveys(10) which could be related to the situation of today. As a result much of his work in this area could be salvaged and used. 
For a modern basemap of the centre of Hobart, use was made of maps $5172-24$ and 5171 4 as published by the Southern Metropolitan Planning Authority. Their accuracy and wealth of detail were ideal for this purpose, providing many clues and 'hidden' information about early lobart Town which otherwise would fot have been apparent.

Notwithstanding all this it is recognised that the reconstruction of carly Hobart Town as now presented is by no means complete.

\section{MAULT'S MAP OF EARLY HOBART TOWN}

The next item of interest is a reconstruction of Collin's Hobart 'Town made by $A$. Mault in the late $1880^{\prime} \mathrm{s}$. This map accompanied J. Backhouse Walker's well-known papers on the sett Iement of Risdon Cove and Hobart Town, and was compiled by Mault from a chart of the Hobart settlement produced by G.P. Harris during the winter of 1804, a copy of Meehan's map of Hobart Town in 1811, and a (then) modern map of Hobart $\mathrm{c}$. 1885.

Of these maps, the Harris map cannot be traced. It is not chart Hobart 10 (also by Harris), now in the files of the Lands Department in Hobart. The reference shown on Mault's map to Meehan's survey plot states that it was taken from "... a plan inscribed 'plan of Hobart Town' approved L. Macquarie, Hobart Town, 30th November 1811. Transmitted to the Surveyor-General in C.S.L. 44/413 of 10 th December".

This last sentence does not occur on Chart Hobart 1 as held in the Lands Department, nor do many of the cadastral and topographical details of Mault's version of Meehan's map appear on this chart and it is clear that Mault must have had access to a more dctailed version of Meehan's survey. This impression is further strengthened by the fact that chart Hobart 1 in the Lands Department is accompanied by a photocopy of a more detailed version of chart Hobart 1 , this photocopy (a) depicting a drawing obviously dating from around the turn of the century, and (b) showing information which required access to Meehan's survey results of 1811 .

There remain however a few minute but possibly significant differences betweee Meehan's survey notes, Mault's copy of the chart in the Lands Department(12) and Mault's map in the Walker Memorial Volume which cannot be explained with the information on hand. Fortunately, they are indeed minute.

Comparing the handwriting and other detail of this photocopy with Mault's map in 'Early Tasmania' it would seem quite probable that Mault is the author of the map shown on the photocopy and that he thercfore would have had access to the more detailed chart of Hobart Town prepared by Meehan in 1811. This chart has not yet been found: if it sti11 exists it may surface one day in Sydney or in London.

In view of the above, it seems therefore reasonable to conclude that

a. Meehan prepared (at least) two manuscript charts of the results of his 1811 survey. Chart number one gave a detailed account of the major features of Hobart Town at that time; it was signed by Macquarie on November 30,1811 and was sent to the SurveyGeneral in Sydney in December (Mault refers to this correspondence as Col. Secr.'s lettex of $44 / 813$ of 10 th December" - so far, it has been impossible to relate this reference to any known documents).

Chart number two is the one now held in the Lands Department, Hobart(13). It is a simplified version of the first one and was handed over by Macquarie to Major Geils on December 1st, $1811(14)$ for his use and guidance.

b. Mault managed to obtain a tracing of the copy that was sent to Sydney in 1811 . He thon made a fair-copy of this tracing after having transferred the main points by pricking them through the tracing onto heavier paper with a pin (these pinpricks clearly show on the photocopy). This fair-copy also has not been found, but the photocopy of this drawing now accompanies chart Hobart 1 in the Lands Department. The very existence of the photocopy means that Mault's fairdrawing was stil1 in existence three or four decades ago and also that if this fair drawing still exists, it is more likely to be still in llobart than anywhere else. 
c. Mault did not have access to or did not bother to analyse Meehan's survey field notes, at that time held in the Lands Department in Sydney. Mault was a very experienced and painstakingly precise maker of detailed engineering survey charts of Hobart around 1890 and certainly would have picked up a few small discrepancies in Meehan's own manuscripts.

Once the situation was understood to be most likely as outlined above the 'Mault Map' became a great help in the interpretation of some of Meehan's more obscure passages. Because of this it is believed that the reconstruction of Meehan's 1811 survey of Hobart Town as now presented is as accurate as his survey observations allow it to be and that any minor errors which may have found their way into the compilation will indeed be minor and will not invalidate the general impression now given by the map.

\section{MEEHAN'S SURVEYING METHODS AND FIELD NOTES}

Meehan worked with a very simple form of theodolite, perhaps the one mentioned in one of Governor King's letters to Collins in 1805(15). This instrument was in fact no more than a compass with a sighting arrangement which revolved around an edge or scale divided into 360 degrees, mounted on a tripod. Distances were measured in chains and links while the direction of each Iine was expressed in a compass bearing down to one half (or sometimes a third) of a degree. The accuracy of such an instrument and working method is not very great and one also has to trust and pray that the convicts working as chainmen for Meehan kept their iron axes and other tools at an appropriate distance from the compass! For these reasons, the bearings of his lines remain the weakest spot in Meehan's work, making it at times very difficult indeed to produce a credible graphic plot of his survey notes. Notwithstanding all these technical problems (compounded by the environment in which he had to work), Meehan was able to deliver quite accurate work most of the time.

Meehan's notebooks were made from a large sheet of paper folded over several times to finish up with a paper size of about $95 \times 150 \mathrm{~mm}$. The centre-fold would then be handstitched into a piece of soft folded leather after which the sides were cut open with a knife. Meehan usually wrote on the righthand pages only and at the end of the pages simply turned around and started again. There are, however, the occasional entries on odd pages which defy all attempts to link their information with material from other pages. Meehan was one of the last surveyors to use the already outmoded 18 th century system of abbreviated notes in longhand and a typical example would be:

$\begin{array}{lll}(13.7) & \text { N11 } 1 \frac{1}{2} \mathrm{E} 530 & \text { bank L. at } 3 \text { is . } 50 \mathrm{~L} \\ (13.8) & \text { N6 } \frac{1}{2} \text { W } 299 & \text { cor of Loanes Garden } \\ (13.9) & \text { edge of bank - at } 1 . \text { beach, } 40 \mathrm{~L} \\ (13.10) & \text { bottom S16W - Side up } 102 / 3 \mathrm{~N}\end{array}$

In this example the details of the bearings and distances are quite clear but the method used to indicate the rest of the detail along the traverse often causes major problems. The numbers at the start of each line are modern references. With the permission and co-operation of the State Archives, each page of the notebook was numbered and the above quotations can therefore be found on page 13, lines 7 to 10 of his 1811 notebook. This method of referencing Meehan's information has proved to be very convenient and helpful, especially during the compilation stages of the graphic plot. There are quite a few of Meehan's fieldbooks still in existence and the Tasmanian State Archives is at present allotting reference numbers to each book.

\section{OTHER HISTORIC MATERIAL FROM MEEHAN'S SURVEY NOTES}

Meehan's survey books also contain many references to people and structures of historical significance.

He refers several times for instance to an 'orphan house' and an 'orphan school' (probably one and the same building) at an unfortunately imprecise location near Antill street. This reference is of great interest, as the existence in Hobart of such an institution as early as 1811 was on $1 y$ vaguely known previously. Other remarks relate to early mills on the Hobart Rivulet (including the one of Mr. Nash), and to a bridge located 
Frank Bolt

in front of today's kodak shop in Elizabeth Street. The location of the powder magazine on the edge of Sullivan's Cove is also shown but subsequent development of the site makes it unlikely that remants will ever come to light.

The implications of some of the measurements noted down in Meehan's notebook are also interesting. The size of the Government House at that time clocated between the modern Franklin Square and the Town Hal1) was a miserable $18.5 \mathrm{~m}$ wide by $5.43 \mathrm{~m}$ deep - hardly enough for four or five small rooms and a narrow passage! The timber church erected over Collin's grave was reputed to be small, and so it proved to be in Meehan's notebook; it measured only $15.3 \times 6.2 \mathrm{~m}$. It also was probably built rather poorly, because 18 months later he notes (in his 1813 surveys) that the church is no longer there. Finaliy the position of the most important place in the settlement was noted: the flagstaff from which the Union Jack signalled the presence of British sovereignty on this is 1 and. In front of this flag Collins used to hold an occasional parade or ceremony, or would read the riot act to that group of Hobart's population who appeared to be in need of such action. Nowadays this spot lies quietly and forgotten underneath the Lord Mayor's reception room in the Hobart Town Hall.

Meehan never hesitated to mention names; especially in his 1813 notebooks a large number of the early inhabitants of Hobart Town get a mention and a further future study of these names should enlarge our knowledge of the pioneers of that period quite considerably.

When in 1813 Meehan surveyed the sandy beach near the 'Government Store' he picked up the ". . tree marked in January 1804." (58.5). This is a very significant remark because of its implications. Meehan spent several months in the Derwent region late in 1803 and early 1804 using Risdon Cove as his base while exploring the surrounding countryside, charting topographical detajls and making general observations as he went along. Chart Monmouth 0 in the Lands Department indicates that one of these excursions went along the mouth of the Hobart Rivulet but Meehan's fieldnotes of this traverse so far have not turned up. The above comment in his notebook indicates however that this visit occurred in January 1804, a few weeks before Collins arrived from Port Phillip with his expedition. The time between the two events is Iong enough for Meehan's opinion of the environment of the Hobart Rivulet to have become known to the inhabitants of Risdon Cove and almost certainly they would have passed these views on to the settlers of Collins advance party who arrived at Risdon early in February and a few days before Collins himself arrived in the 'Ocean'. It is therefore highly likely that it was based on the intelligence of James Meehan that Collins and his party on their exploratory trip of February 17, 1804, went straight to Sullivans Cove, returning that evening to Risdon Cove "... much delighted..." with the decision of "... having pitched on a place about five miles lower down the river" (16).

Nowadays the location of the tree is underneath the pavement near the southernmost corner of the City Hall.

\section{AN ANALYSIS OF THE LOCATION OF MEEHAN'S STREETS}

Because of the very short time available to Meehan during his 1811 visit the 'setting out of the streets of Hobart Town' can not have been more than the placing of a few stakes in the ground, while much of this ground would have been still covered with (burnt?) timber, scrub or rough paddocks.

In Macquarie's proclamation of 1.12.1811(17) he mentioned three 'long' streets (Macquarie, Collins and Liverpool) and four 'cross' streets (Argyle, Elizabeth, Murray and Harrington), while Franklin Square was called George's Square. Davey Street is shown but not named, although on the copy of Meehan's plan which was sent to Sydney it may have been called Pitt Street. The pegging out of Davey Street however was not done till Meehan returned to Hobart in 1813, when he also pegged out the alignments of the other streets which nowadays make up Macquarie's 'regular plan': Molle, Barrack and Campbell Streets and the streets north of and parallel with Liverpool Street.

We need to visualise a series of stakes standing forlorn somewhere in the bush 
(especially north of Liverpool and west of Harrington Street) and it was not until the period of L.t. Governor Davey and Lt. Governor Sorell that the gangs of chain-legged convicts began to clear the spaces botween these stakes and to cover them with crushed sandstone rubble.

The strects in the centre of Hobart by then had been surfaced in some rough-andready manner, especially where these roads left the sandstone of the higher ridges; the bitumen of the intersection of Elizabeth and Collins Street for instance is only a few centimetres thick and is resting directly on solid sandstono. Where however these streets were near creeks use was made of the boulders and smaller pieces of stone in the creek bed to provide a firm surface underfoot - recent excavations in the middle of the Mall in Elizabeth street confirmed just that, precisely 0.9 m underneath the present pavement surface.

There are no known references to the exact reasons which led to the location of the first seven strects as shown by Mochan on his 1811 plan(18). A close study howcvor of the topographical problems which he faced, together with the complications of the existing development (some of which obviously had to be retained) make it quite probable that the following main considerations influenced his decisions very much:

a) Many of the senior officers and merchants had their interests located on the ridge between the Hobart Rivulet and Sullivans Cove and any decision concerning the "base line street' (Meehan called it the 'New Street') was bound to take into account the longterm interest of these people.

b) Collins' Government House was located between the north-eastern boundary of Franklin Square and the south-western entrance of the Town Hall and it becomes obvious that somebody wanted to capitalise on this location: the 'Great Route to the North' (i.e. along the River Derwent into the inland) had to start - and end of course - in front of the steps of Government House.

c) Other important considerations were the retention of easy access to a mill in Liverpool street, access to the paddocks of what is now the Domain and the location of and access to the Commissariat Store (opposite the Prince of Wales Theatre).

Macquarie Street: With the above matters in mind Meehan first surveyed his base line, later to become the N.W. side of Macquarie Street. In fact, one gets the impression from his survey notes that there may already have been plans for a street in this location and orientation: the fact that the rear of the Commissariat Store $\left(215^{\circ} 45^{\prime}\right)$ is virtually parallel with his baseline $\left(214^{\circ} 30^{\prime}\right)$ was noted, together with the fact that the orientation of the store, the width of the future Macquarie Street (100 feet at that point) and the orientation of his Macquarie Street baseline are obviously priority number one on page one of his survey notes. The orientation of his base line was approximately southwest; an orientation further to the south would have made the street too steep near the Anglesea Barracks, while only a fraction more to the west would have led the street into the Hobart Rivulet near the present Molle Street Bridge. Although the baseline went through several parcels of land allocated to various people (including Ingle and Birch), nobody objected as in this manner much land became available for subdivision.

Elizabeth Street: After the baseline from which a rectangular street pattern was to be extended had been clefined on the ground by means of a number of stakes, a few days passed - no doubt to give the interested parties an opportunity to consider the implications of the new situation and to await Macquarie's personal approval after his return from a twoday excursion to the New Norfolk area. This approval must have been readily given, because early on the following day we find Meehan surveying a traverse around the small settlement, in the course of which he picks up the intersection of the early Elizabeth Street and a laneway (now Liverpool Street) in which the mill of Lt. Lord and Mr Collins stood - now the area of the Ellison Hawker bookstore in that street.

A new street leaving Govermment House at right angles to Macquarie Street would run into serious contour problems all the way from its crossing of the Rivulet near the Hospital to the top of Trinity Hill, but would also be at an angle with the front of Government House, an aspect which undoubtedly would have been considered undesirable. 
A further complication was the fact that there already was a vaguely curved road or track, leading from the north-western corner opposite the G.P.o. via the ElizabethCollins Street intersection to near the intersection with Liverpool Street. To avoid a major disturbance of the development already there Meehan commenced his centreline of what was to become Elizabeth Street from the steps of Government House (a spot nowadays covered by a parking strip for motorcycles), but directed this line halfway between the existing bridge across the Rivulet (a spot now covered by the venture Store) and a dogleg bend in the Rivulet next to the National Bank opposite the Venture Store. Luck was with Mechan - his new location of Elizabeth Street finished up nicely on the easier gradients of the western slopes of Trinity Hill.

This location in effect pushed the centreline of Elizabeth Street away from the steps of Government House and to compensate for that, Meehan retained the southwestern boundary of the existing roadway along the Elizabeth Street frontage of the Colonial Mutual build-ing, thus producing a widening of this street near the G.P.O. which still exists. (This early road curving its way from Government House to the bridge across the Rivulet had its origin in the footpath through the bush from the area around the Governor's tent to the flat banks in a bend of the Hobart Rivulet, along which the convict water bearers carried their drinking water which they had scooped out of the rivulet between manferns and tall rising gumtrees...)(19).

Harrington Street: Meehan's baseline (along the northwestern boundary of Macquarie Street) went through Birch's land at right angles, and where it crossed the 'backfence' of Birch (all of 1500 feet removed from the turmoil of Government House!) it seemed a good place for one of Macquarie's cross streets. As much of the land involved was still either virgin bush or semi-cleared land there was no need for this street to be anything else but at right angles to Macquarie Street. This street became Harrington Street. Other streets further to the southwest (Barrack and Molle Streets) were simply orientated parallel with Harrington Street when Meehan staked them out in 1813 . Because however of the increasingly steep slope on the northern side of the rivulet, Molle Street was the last major street in that direction.

Murray Street: In Meehan's survey notes a fence described as 'Capt. Murray's Fence' ran along the present southwestern side of Murray Street from Macquarie Street to a tree on the bank of the Hobart Rivulet, a spot nowadays right underneath the Murray Street entrance of the Centrepoint shopping complex. It is not known on which side of the fence Murray's land was located, if indeed it was Murray's private land at a11. Capt. Murray at that time was the Commandant of Hobart Town and Meehan may well have meant a rectangular area of land which most likely was located on the southwestern side of 'Murray's Fence', and on which for very many years the military were located (now the area of Hadley's Hote1).

It is however obvious that 'Murray's Fence' was a significant landmark and significant enough to determine the direction which Murray Street was to take; this is supported by the fact that the projection of Murray Street towards Sullivans Cove was determined at a later stage in an almost offhand manner - straight through Sgt. McAuley's house and property! (now the site of the Savings Bank of Tasmania). At the northwestern end of Murray Street, steeply increasing slope prevented a continuation much beyond its intersections with Warwick Street, causing many headaches for surveyors in the $1820^{\prime} \mathrm{s}$ and $30^{\prime} \mathrm{s}$.

Argyle Street: This street caused some problems for Meehan and it is clear from his survey notes that he moved the location of his corner stakes on the Macquarie Street baseline several times before he was satisfied. The reason for this is not quite clear; it may be that he simply had some problems in lining his stakes up, while for some as yet unexplained reason the northeastern corner of the Argyle - Liverpool Street intersection apparently also became a 'fixed' point. One thing however soon becomes very clear indeed: the street went straight through the middle of Ingle's land, thus creating valuable frontage for Ingle which was suitable for subdivision.

The intersection of Argyle Street with Macquarie Street produced two very valuable 
comer blocks superbly located, being close to Govemment House, the Commissariat Store, the Landing Place (between the City Hall and the Hope and Anchor Hotel) and the Guard House. It is therefore not surprising that Ingle chose one of these two corner blocks to build on (Ingle Hall - 1814), while Norfolk Island settler James Mitchell built a mirror inage of Ingle Hall (in 1814 or 1815) worth $\$ 2,500$ on the opposite corner block a clever act of civic planning which no doubt aimed to copy the better type of development that went on in London at that time. Many remrants of Mitchell's house are still in existence, but nowadays hide behind the added nodern facade of the Hobart (Town) Hotel (of which the licence incidentally is one of the older ones in llobart).

The gradients of the lower half of Argyle Street were almost better than those of Elizabeth Street, but Elizabeth Street and the track from its northern end through the forest to New Town had the advantage of already having been in use for several years. Argyle street on the other hand still had to be constructed and in the end lost its battle for prominence with Elizabeth Street because its northern end finjshed abruptly on the steep slopes below Stoke Street. Campbel1. Street was to suffer similar problems later on, requiring much public expenditure in later years to put things right.

Liverpool Street: The location of this street was the least difficult as its location was largely controlled by the mill of Lord and Collins(20). This mil1 was 1 ocated on or close to the present site of Ellison Hawker's bookstore in Liverpool Street (near the rear of the premises), and a road or laneway providing access to the mill (and other houses nearby) followed the bank of the Rivulet. Meehan probably was either told or decided for himself not to change this particular situation, while his traverse around the settlement would also have made it clear that he did not have much choice: the southwestern end of the street would either go straight up a steep hili. (as later on Goulburn Street and Forest Road did), or the street would disappear into the Hobart Rivulet halfway between Harrington and Barrack Streets (a street which he added in 1813). Probably for these reasons the orientation of Liverpool Street differs from that of Macquarie Street. In 1813 Meehan linked the Argyle Street intersection of Liverpool Street with the already existing crossing of the Park Street Rivulet, another fixed point, causing a further deviation in the alignment of Liverpool street.

Northwest of Liverpool Street, however, there was iittle or no development other than a few paddocks and for this reason the 1813 streets ... Bathurst. Melville, Brisbane, Patrick and Warwick - are parallel to Macquarie Street - exactly as instructed by Macquarie. For the same reason Molle, Barrack and Campbel1 Streets (dating from 1813) are at right angles to Macquarie Street.

Collins Street: It is not clear why Collins street is almost but not quite para1lel to Macquarie Street. The northeastern end of the alignment had to stay away from the high sandstone cliffs along the Rivulet below the hospital, but also had to avoid a number of houses on the northern side of a lane or street which ran from near the AMP Building to near Hadley's Hotel. By departing from parallelism Meehan avoided major problems for the occupiers, although many of them lost their backyard which became Collins Street - the Collins Street premises of the OBM bookstore for instance is one of the sites the rear boundary line of which is still part of the northwestern side of this lane or street. (It is reasonable to suggest that this lane or street was the direct route between the landing place behind the Hope and Anchor Hotel and the military camp near what is now Hadley's Hotel. When however Macquarie Street was created there was no need to continue the existence of this lane and it was therefore abandoned by Macquarie and Meehan). At the western end of Collins street there was no development to worry about other than a few gardens, and one gets the impression that here Meehan simply halved the distance between Liverpool Street and Macquarie Street.

George's Square (now Franklin Square): The original 1811 concept of the Vi1lage Square and parade ground underwent substantial changes during the course of the 19 th century.

At first this area was developed as a garden surrounding Government House right from Argyle Street through to Murray Street and between Macquarie Street and the water's edge. 
Frank Bolt

In the early 1820's however the Murray Street frontage of this garden (that is: virtually out of sight of Government House) was set aside for public purpose, after which a court house was built in 1823 on the corner with Macquarie Street. In later years more Government offices were built on this strip of land.

Government House was not demolished until the late '50's, an event which was accompanied by a general reorganisation of the area. Elizabeth Street was extended as far as the harbour's edge, while Davey Street was finally extended through to Elizabeth Street not along the easier contours as suggested by Meehan in 1811 (and being the location of an old track leading from Government House to Knopwood's Cottage Green) but in a straight line from Murray Street through to Victoria Dock.

Argyle Street was also extended from Macquarie Street to the waterfront and the ratepayers of Hobart thus obtained a new city block on which to build one of the finest Town Halls in Australia - 1866. What remained of the original idea of a Village Square was then again cut up: the western part was reserved for extensions to the Government Offices in Murray Street (this site is now occupied by the Premier's Department and the Court Buildings), while the eastern section was Iandscaped and re-named Franklin Square.

\section{MACQUARIE'S BUILDING REGULATIONS}

During the first few years after 1804 the early settlers used whatever building materials they could find and many of these materials came from the resources of their environment.

With so much timber on hand, split planks and palings were soon used for almost everything and most of the common building methods of rural Tasmania in the mid-80's were formulated in the early days of the colony. Meehan referred already in 1811 to paling fences, and also noted that the decking of the bridge across the Hobart Rivulet consisted of 'planking': solid slabs of timber, a construction method still used in the country today. Planking was also used for (often vertical) weatherboards and for interior lining, thin shingles for the roof. Those with more money to spend would use bricks instead of rubble or boulders for the fireplace, while the next step 'up' would be to build the front elevation out of bricks. Buildings entirely built of bricks or stone were notable landmarks in any street and the owners of such houses would have been very rich indeed compared with the rest of the population. If we add to this a generally poor standard of housing, the poorly constructed 'roads' (often no more than muddy tracks) and a generally unhygienic sanitary situation which favoured rats and other vermin, one can well imagine the horror with which Macquarie observed the existing situation in Hobart. Obviously, nothing worthwhile had been done to improve general housing standards, no land had been set aside for public building and amenities, most houses were too small and too close together and no thought had been given to an orderly development of Hobart Town either for that time or later.

Seen in this light the measures which Macquarie took were not dictatorial but very sensible indeed. In order to get the individual homes further apart he specified minimum widths of allotments - 60 or 100 feet, while all allotments had to be 132 feet deep, thus permitting each household to grow its own vegetables and to dispose of its nightsoil within its own boundaries. For an orderly placing of these allotments streets were needed and the frontages created by Meehan's formal streets would allow the subdivision of many of the required blocks of land. All streets were to be 60 feet wide, with footpaths 8 feet wide set aside for pedestrians. In addition, buildings had to be set back 20 feet from the street, thus creating a 100 feet minimum width between street facades. This last ruling was adhered to for qui te a number of years and is the reason why such buildings as Ingle Hall still enjoy a garden in the middle of the city. In later years the authorities relaxed this requirement, especially in the city centre and many merchants used this space for a shop or other premises. As a result, many of the older Hobart buildings can still be recognised by a careful study of their construction behind their street frontage.

The 100 feet rule also had another purpose "... in this plan the houses are intended 
to be 100 feet apart in the lines and the reason of intersecting the streets acutely is not to intefere with many houses which are now erected and which, if disposed of in a regular plan, must be entirely destroyed"(21). The problems of hardship that confronted Meehan when he had to decide where to locate the new streets have already been referred to earlier, and the 20 -feet setback created a convenient margin which the authorities could use in difficult cases.

This they did and although the documents from the Davey and Sorell periods are full of cases in which people had to give up their house because it was located in the way of advancing convict road gangs, there are other cases where buildings lingered on for quite some years. Lands Department Chart Hobart 5 of about 1829 shows a number of such buildings (a notable case is in Bathurst Street between Argyle and Campbell Streets), and even Calder's survey notes of 1834 chart a number of cases which could possibly relate to 1811 or earlier.

\section{REFLRENCES}

The interpretation in this paper and in the accompanying map of Meehan's survey notes of 1811-1813 is entirely my own. There are no known documents to 'prove' any of the conclusions that have been reached in this paper. These conclusions are reasonable in the light of the evidence available and with this evidence in hand it would be difficult to think of significantly different explanations of the way in which Meehan laid down the street pattern of central Hobart.

The detail shown on the map is not complete, but it is hoped that it will encourage others with other background knowledge to add to it in years to come.

The main sources of information were Meehan's survey notebooks of 1811 and 1813(22), the various charts in the Lands Department of early Hobart Town (including those quoted in the text), and a large number of early title surveys in central Hobart now filed in the Lands Department.

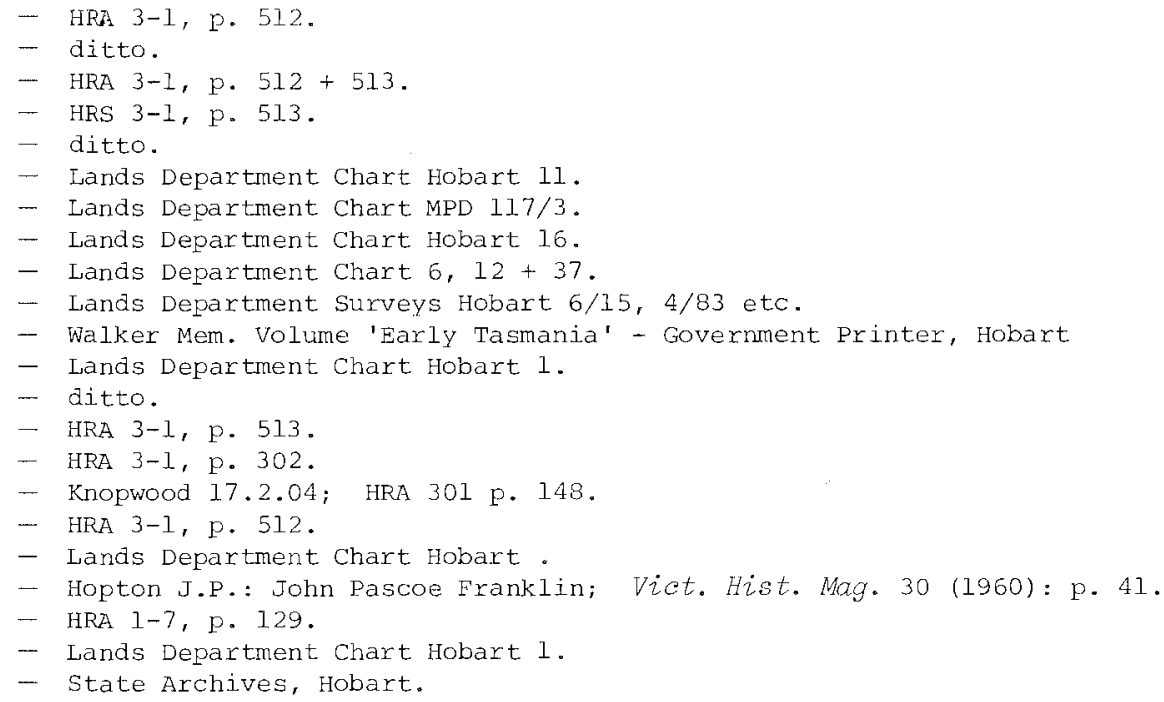


Frank Bolt

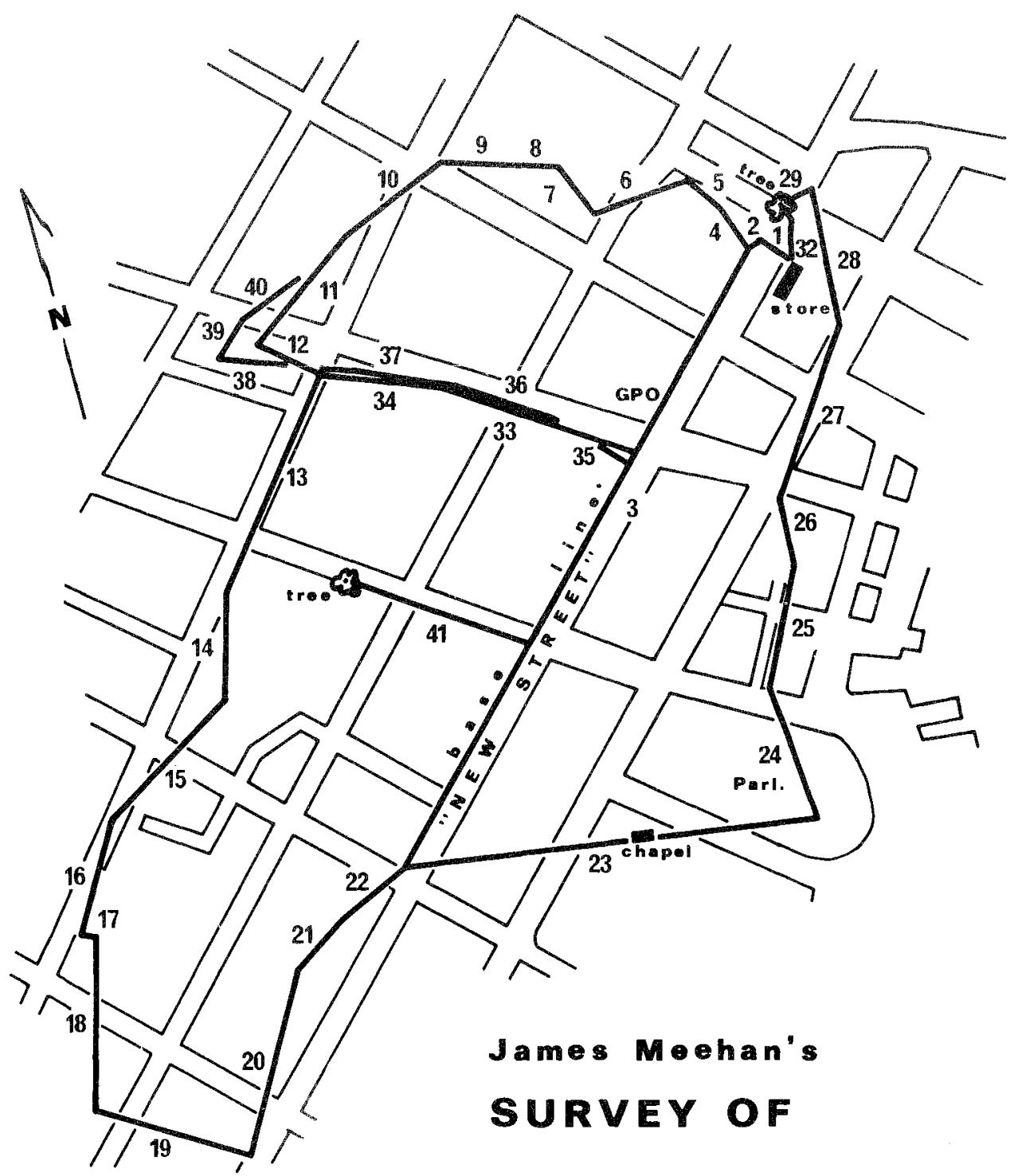

HOBART TOWN-1811

details of the central main traverses

fig. 2 


\section{APPENDIX}

JAMES MEEHAN'S SURVEY OF HOBART TOWN (see fig. 2)

As an example of Meehan's survey methods, this diagram shows the survey traverse encircling the settled area of early Hobart Town, an area now covered by Central Hobart.

In view of the primitive equipment used by Meehan the outer traverse and its link with line 3 (the survey baseline along Macquarie Street) closes with a surprising degree of accuracy.

Note how the location of the traverse along an early traffic way (1ines 33 and 34) differs from today's location of Elizabeth street. This traverse however does not quite meet the junction of 1 ines 12 and 13 , although in all probability it did as measured by Meehan.

Line 29 terminated on a small beach near a tree which had been blazed by Meehan in January 1804, thus making it the first survey benchmark in Hobart.

Line 1 and Line 32 connected with the northern corner of the 'provision' (Government) Store. When Meehan made his survey in November 1811 this building had only just been completed. It is still in existence in Macquarie Street opposite the Prince-ofWales Theatre; it now serves as an office for the Tasmanian Museun and Art Gallery.

Line 41 (along Murray Street) was in all probability the front fence of the early military barracks area, while the tree at the end of this line stood on the bank of the Hobart Rivulet - a spot now covered by the entrance of the Centrepoint complex.

Line 23 was orientated in such a way that it went alongside a small chapel over Collins' grave; the fieldnotes of this line are detailed enough to attempt the reestablishment of the exact location of this first chapel or church in Tasmania. Another interesting aspect of this line is that at that time it was apparently still possible to see from St. Josephs Church in Macquarie Street to a spot in front of Parliament House!

Meehan gives the following details about the traverses as shown on the adjoining page. For convenience of reference, they have been numbered here from 1 through to 41 :

$\begin{array}{llrrllrlrlr}3.8 & \text { W40.5N } & 147 & 15 & 11.10 & \text { W41.75S } & 700 & 29 & 13.17 & \text { W23.5S } & 149 \\ 3.9 & \text { W25.5S } & 49 & 16 & 11.11 & \text { S20.33W } & 519 & 30 & 14.3 & \text { S32.75E } & 90 \\ 3.11 & \text { S34.5W } & 3066 & 17 & 11.16 & \text { E15S } & 65 & 31 & 3.6 & \text { N34.75E } & 46 \\ 8.5 & \text { N31.75W } & 215 & 18 & 11.18 & \text { S16W } & 753 & 32 & 3.4 & \text { N } 1.75+\mathrm{E} & 142 \\ 8.15 & \text { W43.5N } & 186 & 19 & 21.1 & \text { E21.5S } & 703 & 33 & 20.3 & \text { W23.5N } & 900 \\ 9.1 & \text { W14.25 } & 430 & 20 & 12.4 & \text { N20E } & 833 & 34 & 20.7 & \text { W11N } & 510 \\ 9.6 & \text { N32.5W } & 249 & 21 & 12.8 & \text { E43.33N } & 286 & 35 & 5.11 & \text { W36N } & 400 \\ 9.16 & \text { W } 7.75 & 181 & 22 & 12.14 & \text { E33N } & 360 & 36 & 5.12 & \text { W21N } & 450 \\ 10.5 & \text { W } 6.5 \mathrm{~N} & 319 & 23 & 12.15 & \text { E1.5N } & 1800 & 37 & 6.4 & \text { W14.25N } & 427 \\ 10.8 & \text { W33S } & 524 & 24 & 13.4 & \text { N14.67W } & 598 & 38 & 6.7 & \text { W11.75N } & 584 \\ 10.11 & \text { S44.33 } & 620 & 25 & 13.7 & \text { N16.5E } & 530 & 39 & 7.1 & \text { N37.5E } & 202 \\ 10.12 & \text { E29.5+S } & 310 & 26 & 13.8 & \text { N6.5W } & 299 & 40 & 7.3 & \text { E30N } & 303 \\ 10.16 & \text { S28.33W } & 1005 & 27 & 13.11 & \text { N24E } & 800 & & & & \\ 11.6 & \text { S } 7.75 W & 500 & 28 & 13.12 & \text { N6.67Q } & 600 & 41 & 16.9 & \text { W24N } & 850\end{array}$

